Nuclear waste may be stored in synthetic rock

High level nuclear waste may be locked into a synthetic mineral which is far more stable than the borosilicate glasses under development for the purpose in Europe and the US, an Australian geochemist said last week. Whereas glassified waste may devitrify when exposed to ground water at high temperature and pressure, thus exposing a large surface area for the dissolution of the radionuclides in the glass, the new mineral-'synroc'should be as stable as a natural rock.

The scientist responsible, Professor A. E. Ringwood of the Australian National University, told Nature this week that "if people are prepared to pay the cost, they can get any degree of containment they require". The cost, Ringwood estimates, of the basic synroc process would be about $1 \%$ of the cost of the energy produced by the nuclear material from which the waste came.

"Our present system is just one example among many possibilities" said Ringwood. The objective was to pro- duce crystalline minerals, related to known stable types, which would contain the dangerous radionuclides in a solid solution. The present synroc contains: perovskite $\left(\mathrm{CaTiO}_{3}\right)$, "very effective at dissolving rare earths and strontium"; a hollandite-like mineral $\left(\mathrm{Ba},(\mathrm{K}) \mathrm{AlTi}_{3} \mathrm{O}_{8}\right)$, capable of dissolving molybdenum, ruthenium, and rhodium; a cubic form of zirconia ( $\left.\mathrm{ZrO}_{2}\right)$, "a very refractory mineral which dissolves the long-lived actinides including uranium"; barium feldspar ( $\left.\mathrm{BaAl}_{2} \mathrm{Si}_{2} \mathrm{O}_{3}\right)$, which can immobilise barium, potassium, rubidium and caesium; and two others, calsilite $\left(\mathrm{KAlSiO}_{4}\right)$ and lucite $\left(\mathrm{KAlSi}_{2} \mathrm{O}_{6 \mathrm{i}}\right)$ which can also dissolve caesium and rubidium. The mixture of minerals melts at $1,280{ }^{\circ} \mathrm{C}$-low enough to use the same technology that produces borosilicate glass.

Ringwood's recipe is to melt $90 \%$ of the mixture with $10 \%$ of calcined high level waste, and recrystallise. It then forms a stable fine-grained rock "rather like a basalt". The waste is dis-

solved in the individual mineral crystals. "We are then proposing to bury the synroc 1 to $3 \mathrm{~km}$ down in impervious granite-one with few cracks" said Ringwood. Then little ground water will get to it; but any that does will find the mineral stable.

"We have demonstrated that the problem is soluble. But there can be variations". There may still be a problem in that there is an excess concentration of waste elements at the surfaces of the mineral crystals. But Ringwood believes he can deal with that: "leave the synroc for 20 years, crush it and wash in nitric acid to remove the surface-bound elements. Return the washings to the beginning of the whole process. Mix the remainder 1 to 4 with alumina and zirconia. Hot press the mixture into inert cylinders. Then no geological process could get it out." Cost of this fail-safe process? About $3 \%$ of energy costs.

Robert Walgate

\title{
Royal Society slams routine toxicity tests
}

Most of the $£ 50$ million spent in the UK each year on the toxicity testing of new chemicals and drugs is wasted on "routine tests of limited value", says a Royal Society report published last week. These tests involve "the routine of exposure of many animals without attention to mechanisms. Only if mechanisms are understood is it possible to extrapolate toxicity measurements across species and from the large doses used in experimental animals to the exposures experienced by man, commonly a thousand-fold smaller",

More funds should be made available in the UK to study toxicology as an academic discipline and to identify people at risk from the effects of hitherto unknown toxic materials. These are the two main recommendations of the report which was produced by a Royal Society study group set up in 1975 under the Chairmanship of Sir Richard Doll to study long-term toxic effects.

As well as the mechanisms of toxicity other specific topics for further study recommended by the report include:

- the effect of nutritional and other variables on susceptibility to toxic effects;

- the carcinogenicity of chemical products. Current tests, says the report, are unlikely to provide a quantitative mieasure of carcinogenic risk to man. - systems for monitoring trends in human disease. These are adequate for providing data on mortality but give little information on the prevalence of non-lethal disease. The report recommends that the possibility of extending the work of the Office of Population Censuses and Surveys to include regular monitoring of ill-health should be considered.

The report also recommends that systems for monitoring the health of industrial workers exposed to new chemicals should be improved. Results of experiments on animals to test the toxicity of new materials cannot be extended to humans, it says, because of the lack of theoretical knowledge of the mechanisms of toxicity in different species. Hospital discharge and mortality data should also be linked to records of exposure to industrial and other hazards.

\section{Queue for life science in space}

THe: National Aeronautics and Space Administration has received an unexpectedly heavy response to its call for proposals for life sciences experiments to be carried out on Spacelab missions in 1981 and 1983.

"So far we have received over 340 proposals, and more are still coming in. This is an extremely large turn-out; in particular detailed proposals have been received from over $50^{\prime \prime \prime}$, of those who originally submitted letters of intent,"
Dr David Winter, director of the life sciences programme at NASA, said last week.

Research areas from which the experiments will be selected include endocrinology and vestibular function, embryology, developmental biology and plant growth.

"The main attraction of Spacelab is the opportunity it provides for studying the role of gravity in life processes," according to Dr Winter. The presence of scientists will also allow "hands-on" experiments to be tried out, in contrast to previous life-science experiments in space which were fully automated.

"A number of the studies will be concerned with the behaviour of the human body in space. For example, there is a large redistribution of fluid and blood within the body in the first hours in space; whereas it would not be possible to carry out experiments at this early stage on crew members flying the vehicle, it will be possible to carry out studies on the experimenters themselves."

The potential contribution of such studies to later space shuttle flights was one of the factors which persuaded the Senate commerce committee to authorise an additional $\$ 2$ million for the administration's budget request of \$40.6 million in 1979 for life science experiments.

The high level of interest shown by life scientists is also being used by the agency to support attempts to increase the budget for life sciences in the 1980 budget.

David Dickson 